\title{
PROGRAM KELOMPOK MENTORING BISNIS KOMUNITAS TANGAN DI ATAS WILAYAH JAKARTA SELATAN 5.0
}

\author{
Bambang Eko Samiono ${ }^{1 *}$, Hanny Nurlatifah ${ }^{1}$ \\ ${ }^{\text {I} P r o g r a m ~ s t u d i ~ M a n a j e m e n, ~ F a k u l t a s ~ E k o n o m i ~ d a n ~ B i s n i s, ~ U n i v e r s i t a s ~ A l ~ A z h a r ~ I n d o n e s i a, ~}$ \\ Jl. Sisingamangaraja, Kompleks Masjid Agung Al Azhar, Kebayoran Baru, Jakarta Selatan 12110. \\ Email penulis korespondensi: be.samyono@uai.ac.id
}

\begin{abstract}
Abstrak
Komunitas Tangan Di Atas wilayah Jakarta selatan (TDA Jaksel) merupakan salah satu TDA Wilayah dibawah TDA Pusat dan merupakan pusat penggerak kegiatan dalam organisasi. Prioritas kegiatan utama TDA Jaksel adalah mengadakan peningkatan capacity building bagi anggotanya. Salah satu program TDA Jaksel untuk meningkatkan kemampuan manajemen dan pengelolaan usaha anggotanya adalah program Kelompok Mentoring Bisnis (KMB). Tahun 2018, KMB menggunakan format yang lebih terstruktur dengan konsep berkurikulum dan diikuti oleh member yang berbayar. Peserta program KMB berjumlah 32 orang yang terbagi dalam 4 group berdasarkan pilihan terhadap mentornya. Permasalahan yang ditemui pada saat evaluasi di pertengahan program KMB adalah ketidakefektifan dalam KMB. Team Pengabdian masyarakat bekerjasama dengan TDA Jaksel membantu memberikan solusi dengan menerapkan konsep efektifitas pelatihan melalui: pengelompokan kembali group program mentoring berdasarkan level bisnisnya, menyusun kurikulum mini/SAP untuk group basic, memberikan sesi mentoring sesuai SAP serta melakukan evaluasi. Sementara untuk pembekalan yang dilakukan oleh Team Pengabdian masyarakat UAI difokuskan pada kelompok basik yang berjumlah 6 orang dan sesi pertemuan dalam 4 tahap yang memadukan metode mentoring dan coaching. Di akhir program diperoleh evaluasi bahwa kepuasan dalam pelaksanaan program KMB ini meningkat 25\% setelah dilakukan pengelompokan ulang dan dibenahi materi serta metode pengajarannya.
\end{abstract}

Kata kunci: Bisnis, Elearning, Mentoring, Startup, TDA, Training, Wirausaha,

\begin{abstract}
TDA Wilayah Jakarta Selatan (TDA Jaksel) is one of TDA wilayah under TDA Pusat and is the driving center for activities in the organization. TDA Jaksel's main priority is to increase capacity building for its members. One of the South Jakarta TDA programs to improve the management and management capabilities of its members is the Kelompok Mentoring Bisnis (KMB) program. In 2018, KMB uses a more structured format with curriculum concepts and paid members only. 32 participants of the KMB program were divided into 4 groups based on their choice of mentor. The problem encountered during the evaluation in the middle of the KMB program was the ineffectiveness of the KMB. The Community Service Team in collaboration with TDA Jakarta helped provide solutions by applying the concept of training effectiveness through: grouping back mentoring programs based on their business level, compiling mini / SAP curriculum for the basic group, providing mentoring sessions according to SAP and conducting evaluations. While for the debriefing conducted by the UAI Community Service Team, the focus was on the basics group, which consisted of six people and meeting sessions in four stages, which combined mentoring and coaching methods. At the end of the program, an evaluation was obtained that satisfaction in the implementation of the KMB program increased by $25 \%$ after regrouping and fixing the material and teaching methods.
\end{abstract}

Keywords: Business, E-learning, Mentoring, Startup, TDA, Training, Entrepreneurship, 


\section{PENDAHULUAN}

TDA Jaksel merupakan sebuah komunitas bisnis start-up sebagai basis penggerak kegiatan dalam organisasi karena merupakan merupakan basis massa dan pusat kegiatan serta telah memiliki kepengurusan yang di sahkan oleh TDA Pusat sebagai badan tertinggi. Secara demografi struktur keanggotaan yang ada tidaklah berbeda dengan wilayah lainnya dimana dominasi member adalah start-up business dalam bidang retail dan dijalankan melalui online shop.

Dengan kondisi demografi mayoritas anggota yang merupakan pengusaha start up dan merupakan konsen dari visi mereka untuk mencetak pengusaha terkemuka, TDA Jaksel mempunyai komitmen untuk meningkatkan kapabilitas anggotanya melalui berbagai program pemberdayaan dan pembekalan. Salah satu program major yang selalu dilakukan setiap tahun adalah program Kelompok Mentoring Bisnis (KMB).

Di tahun 2018, KMB menggunakan format yang lebih terstruktur dengan konsep berkurikulum yang telah disusun tim edukasi TDA Jaksel dan hanya diikuti oleh member yang berbayar sebagai wujud komitmen mereka. Tahun ini peserta program KMB berjumlah 32 orang yang terbagi dalam 4 group berdasarkan mentor yang mereka pilih. Masing-masing group mendapat 2 mentor dan menjalankan program KMB selama 8 pertemuan sesuai dengan kurikulum yang digunakan.

Saat dilakukan eveluasi di pertemuan ke 4 ditemukan beberapa temuan dilapangan. Diantaranya adalah ketidak efektifan program KMB yang berjalan karena ketidak homogennya level bisnis tiap group sehingga tujuan dari setiap materi tidak maksimal, Progres KMB tiap group tidak sama yang disebabkan oleh ketidaksamaan keaktifan mentor dan anggota tiap kelompok tersebut serta komitmen peserta KMB yang rendah untuk mengikuti program KMB hingga selesai. Beberapa permasalahan ini harus segera diselesaikan sehingga sisa pertemuan program KMB yang berjalan bisa terlaksana sesuai dengan tujuan diadakannya KMB.

Dari paparan diatas dapat disimpulkan beberapa hal yang menjadi permasalah bagi Mitra (TDA Jaksel) dalam menjalankan program $\mathrm{KMB}$ diantaranya:

Ketidakefektifan program KMB yang berjalan.

(2) Ketidaksamaan progress pelaksanaan KMB yang disebabkan karena perbedaan keaktifan antara mentor dan peserta KMB. (3) Rendahnya komitmen peserta KMB untuk mengikuti program KMB ini hingga usai.

Menelaah permasalahan yang dihadapi oleh Mitra ini, maka tim pengabdian masyarakat UAI bekerjasama dengan divisi edukasi Internal TDA Jaksel bekerjasama sebagai kontribusi untuk fokus terhadap permasalahan yang dihadapi mitra yaitu berupa ketidak efektifan program KMB yang bisa diuraikan menjadi beberapa detail akar permasalahan. Diantaranya: (1) Kesalahan dalam konsep pembentukan group KMB di awal proses, (2) Ketidak tersedia kurikulum yang sesuai dengan level bisnis, (3) Ketidaksesuaian mentor dalam mengajar dengan level binis peserta.

Sehingga dengan demikian tujuan yang ditetapkan dalam program pengabdian masyarakat adalah memberikan solusi terhadap permasalahan utama yang dihadapi TDA Jaksel yaitu: (1) Memperbaiki konsepnya ulang program KMB pada kepengurusan TDA Jaksel 5.0. baik pengemlompokan maupun kontennya. Serta (2) mengevaluasi kepuasan peserta group basic setelah dilakukan perbaikan konsep tersebut

\section{METODE PELAKSANAAN}

Pelaksanaan pengabdian masyarakat dengan mitra TDA Jaksel dilaksanakan selama empat bulan yaitu dari Desember 2017 hingga bulan April 2018. Pelaksana pengabdian masyarakat terdiri dari Team pengabdian masyarakat UAI yaitu dari Dosen dan 2 mahasiswa serta Team TDA Jaksel yang diwakili oleh Divisi Edukasi Internal TDA Jaksel 5.0. Dalam pelaksanaan pengimplementasian program Tim pengabdian masyarakat UAI bekerjasama dengan Divisi Edukasi Internal TDA Jaksel melakukan evaluasi di paruh program KMB yang telah berjalan. Pengevaluasian ini dilakukan setelah dilapangan ditemui ketidak efektifan dalam pelaksanaan KMB baik yang diutarakan oleh mentor maupun member. Tindakan perbaikan tersebut adalah mengupayakan peningkatan efektifitas KMB melalui proses desain instruksional, yaitu suatu pendekatan yang sistematis untuk mengembangkan program pelatihan. Team pengabdian masyarmengambil teori pelatihan disain pelatihan yang efektif yang dikemukakan oleh Yuwono (2005). Pada konsep 
ini pelatihan yang efektif merujuk pada gambar berikut:

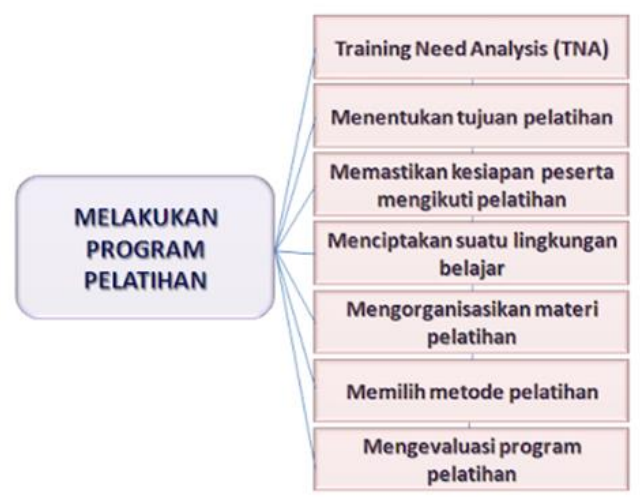

Gambar 1. Konsep Pelatihan yang Efektif

Mengingat program KMB yang akan dilaksanakan ini merupakan upaya perbaikan dari program yang sebelumnya berjalan maka tim pengabdian masyarakat UAI mengambil 3 langkah perbaikan yang mengadopsi konsep diatas yaitu: (1) Menciptakan satu Lingkungan Belajar (Melakukan pengelompokan ulang terhadap group program KMB). (2) Mengorganisasikan Materi Pelatihan (Penyusunan SAP kewirausahaan). (3) Memilih Metode dan Menjalankan Pelatihan (Mentoring group Baru)

\section{HASIL DAN PEMBAHASAN}

Kegiatan pengabdian masyarakat pada Komunitas TDA Jaksel melalui program KMB ini berjalan setelah dilakukannya evaluasi terhadap program tersebut oleh divisi edukasi internal TDA Jaksel, perwakilan mentor dan tim pengabdian masyarakat UAI. Berikut paparan mengenai realisasi hasil evaluasi terhadap program KMB TDA Jaksel:

\section{Menciptakan satu Lingkungan Belajar: (Melakukan pengelompokan ulang terhadap group program KMB)}

Upaya untuk mengubah susunan anggota pada group program mentoring dengan dasar level bisnis diambil dengan pemikiran agar terjadi homogenitas didalam satu group sehingga dengan mudah mentor memberikan pengajarannya. Dampak akhir yang ingin dicapai adalah adanya partisipasi peserta program KMB untuk dapat menerapkan materi kewirausahaan ini untuk di terapkan pada bisnis masing-masing, sehingga memberikan peningkatan kinerja di dalam bisnis mereka. Pada tahap evaluasi dan pengelompokan ulang peserta program KMB ini, data 32 peserta ayng aktif mengikuti program KMB ini kembali di telaah dan pada akhirnya dikelompokkan ulang dan dibagi dalam 4 group yang masing masing group mendapat 1-2 mentor yaitu: (1) Group Intermediate : 1 group: beromset $>\mathrm{Rp} 300$ Juta /tahun (2) Group Beginer : 2 group: beromset Rp 50-300 Juta /tahun (3) Group Basic : 1 group : beromset $<\mathrm{Rp} 50$ Juta /tahun

Khusus pembahasan untuk group basic yang merupakan group binaan Team pengabdian Masyarakat UAI, Group basic ini mempunya 6 orang anggota yang rata-rata merupakan karyawan yang berkeinginan untuk mempunyai usaha atau telah mempunyai usaha namun tidak dilakukan secara konsisten. Detail data mereka sebagai berikut:

Tabel 1. Data Peserta di group basic

\begin{tabular}{|c|c|c|c|}
\hline No & Identitas & Omset & Status \\
\hline 1 & $\begin{array}{l}\text { Henny } \\
\text { (henny.hastuti@gmail.com) }\end{array}$ & 0 & $\begin{array}{l}\text { Karyawan } \\
\text { merintis } \\
\text { usaha }\end{array}$ \\
\hline 2 & $\begin{array}{l}\text { Tia Bahrawi } \\
\text { (tia.bahrawi@gmail. } \\
\text { com) }\end{array}$ & 0 & $\begin{array}{l}\text { Karyawan } \\
\text { merintis } \\
\text { usaha }\end{array}$ \\
\hline 3 & $\begin{array}{l}\text { Jamhur } \\
\text { (jamhur.sc@gmail. } \\
\text { com) }\end{array}$ & 0 & $\begin{array}{l}\text { Karyawan } \\
\text { usaha } \\
\text { berhenti }\end{array}$ \\
\hline 4 & $\begin{array}{l}\text { Dwiyanto } \\
\text { (dwiyanto1381@gmail.com) }\end{array}$ & 0 & $\begin{array}{l}\text { Karyawan } \\
\text { dengan usaha } \\
\text { sampingan }\end{array}$ \\
\hline 5 & $\begin{array}{l}\text { Widyanto } \\
\text { (widyanto111@gmail.com) }\end{array}$ & 0 & $\begin{array}{l}\text { Karyawan } \\
\text { merintis } \\
\text { usaha }\end{array}$ \\
\hline 6 & $\begin{array}{l}\text { Fikri Abet } \\
\text { (fikriabet@yahoo. } \\
\text { com) }\end{array}$ & 0 & $\begin{array}{l}\text { Mahasiswa } \\
\text { merintis } \\
\text { usaha }\end{array}$ \\
\hline
\end{tabular}

\section{Mengorganisasikan Materi Pelatihan: (Penyusunan SAP kewirausahaan) untuk group basic: \\ Pada kegiatan pengabdian masyarakat ini} fokus kegiatannya team pengabdian masyarakat UAI adalah menyusun kurikulum mini/SAP untuk group basic sekaligus mengajarkannya. Pada kurikulum group basic perbedaan yang utama dari kelompok yang lain adalah dalam hal tujuan program ini. Dimana tidak saja pemberian materi kewirausahaan yang harus diberikan namun juga materi motivasi. Untuk materi kewirausahaan dibuat dalam bentuk lembar kerja yang diharapkan bisa memacu mereka untuk segera merealisasikan ide-ide bisnis yang ada dalam bisnis yang nyata. Materi motivasi dan kewirausahaan ini mencakup: 
Tabel 2. Materi Pembelajaran Motivasi dan

Kewirausahaan

\begin{tabular}{|c|c|c|}
\hline SESI & MATERI & AKTIFITAS \\
\hline $\begin{array}{l}\text { Mentoring } \\
\text { sesi } 1\end{array}$ & $\begin{array}{l}\text { Materi motivasi \& } \\
\text { goal setting }\end{array}$ & $\begin{array}{l}\text { - Mengisi lembar } \\
\text { kerja goal setting } \\
\text { - Mengisi lembar } \\
\text { kerja time table }\end{array}$ \\
\hline $\begin{array}{l}\text { Mentoring } \\
\text { sesi } 2\end{array}$ & $\begin{array}{l}\text { Materi Bisnis } \\
\text { Model Canvas }\end{array}$ & $\begin{array}{l}\text { - Lembar kerja BMC } \\
\text { terisi }\end{array}$ \\
\hline $\begin{array}{l}\text { Mentoring } \\
\text { sesi } 3\end{array}$ & $\begin{array}{l}\text { Marketing } \\
\text { Strategi }\end{array}$ & $\begin{array}{l}\text { - Lembar kerja } \\
\text { marketing strategi } \\
\text { terisi }\end{array}$ \\
\hline $\begin{array}{l}\text { Mentoring } \\
\text { sesi } 4\end{array}$ & $\begin{array}{l}\text { Materi Keuangan } \\
\& \text { evaluasi } \\
\text { penutupan }\end{array}$ & $\begin{array}{l}\text { - Lembar kerja } \\
\text { keuangan terisi } \\
\text { - Kompilasi lembar } \\
\text { kerja }\end{array}$ \\
\hline
\end{tabular}

\section{Memilih Metode dan Menjalankan} Pelatihan: (Mentoring Group Baru)

Mentoring group baru dilaksanakan selama 4 kali pertemuan yang berjalan antara bulan april dan mei 2018. Pelaksanaan dilakukan di Universitas Al Azhar Indonesia dengan durasi 2 jam persesi. Materi yang diberikan sesuiai dengan SAP yang telah dibuat dengan memberikan materi diawal sesi dan dilanjutkan dengan pengisian lembar kerja dan membahas lembar kerja yang dikerjakan secara individu. Peserta aktif sebanyak 4 orang yang terus mengikuti program hingga usai sementara 2 lainnya tidak menyesaikan sesi mentoring dan tidak pernah hadir. Dengan daftar kehadiran sebagai berikut:

Tabel 3. Daftar Kehadiran peserta KMB

\begin{tabular}{llcccc}
\hline No & \multicolumn{1}{c}{ Identitas } & $\begin{array}{c}\text { Sesi } \\
\mathbf{1}\end{array}$ & $\begin{array}{c}\text { Sesi } \\
\mathbf{2}\end{array}$ & $\begin{array}{c}\text { Sesi } \\
\mathbf{3}\end{array}$ & $\begin{array}{c}\text { Sesi } \\
\mathbf{4}\end{array}$ \\
\hline $\mathbf{1}$ & $\begin{array}{l}\text { Henny } \\
\text { (henny.hastuti@gmail.com) }\end{array}$ & $\mathrm{x}$ & $\mathrm{x}$ & $\mathrm{x}$ & $\mathrm{x}$ \\
$\mathbf{2}$ & $\begin{array}{l}\text { Tia Bahrawi } \\
\text { (tia.bahrawi@gmail.com) }\end{array}$ & $\mathrm{x}$ & $\mathrm{x}$ & $\mathrm{x}$ & $\mathrm{x}$ \\
$\mathbf{3}$ & $\begin{array}{l}\text { Jamhur } \\
\text { (jamhur.sc@gmail.com) }\end{array}$ & $\sqrt{ }$ & $\sqrt{ }$ & $\sqrt{ }$ & $\mathrm{x}$ \\
$\mathbf{4}$ & $\begin{array}{l}\text { Dwiyanto } \\
\text { (dwiyanto1381@gmail.com) }\end{array}$ & $\sqrt{ }$ & $\sqrt{ }$ & $\sqrt{ }$ & $\sqrt{ }$ \\
$\mathbf{5}$ & $\begin{array}{l}\text { Widyanto } \\
\text { (widyanto111@gmail.com) }\end{array}$ & $\sqrt{ }$ & $\sqrt{ }$ & $\sqrt{ }$ & $\sqrt{ }$ \\
$\mathbf{6}$ & $\begin{array}{l}\text { Fikri Abet } \\
\text { (fikriabet@yahoo.com) }\end{array}$ & $\mathrm{x}$ & $\sqrt{ }$ & $\sqrt{ }$ & $\sqrt{ }$ \\
\hline
\end{tabular}

\section{Mengevaluasi Program: (Survey Kepuasan)}

Diakhir sesi dibagikan kuisioner mengenai tingkat kepuasan dengan menggunakan metode Customer Satisfaction Index (CSI) dalam mengikuti program KMB ini. Evaluasi ini untuk mengukur kepuasan peserta dalam mengikuti program ini sebelum dan setelah perubahan materi dan SAP. Pertanyaan tersebut mengenai: 1) Pendapat mengenai program KMB ideal yang diinginkan 2) Pendapat mengenai program
KMB sebelum masuk ke group basic, 3) Pendapat mengenai program KMB basik di UAI.

Hasilnya terlihat bahwa: 1) Hasil perhitungan Customer Satisfaction Index (CSI) pada program kelompok mentoring bisnis sebelum pengelompokan ulang sebesar: $65.3 \%$, 2) Hasil perhitungan Customer Satisfaction Index (CSI) pada program kelompok mentoring bisnis setelah pengelompokan ulang sebesar: $90.7 \%, 3)$ Terjadi kenaikan tingkat kepuasan hingga 25,4\% setelah dilakukan perubahan. 4) Kenaikan tingkat kepuasan tertinggi mencapai 6,7 hingga 8,25 point terjadi pada item: Program KMB dilaksanakan di ruangan khusus (Tangibles), Program KMB di dukung materi yang tepat sesuai kebutuhan mentee (Reliability) dan Lembar kerja program KMB memberikan kemudahan untuk diterapkan oleh mentee (Assurance)

Beberapa komentar dan saran yang di berikan mentee adalah: 1) Diharapkan pembagian mentor sesuai passion dari mentee, 2) Program KMB group basic yang dilaksanakan di UAI merupakan model pembelajaran yang sangat ideal (baik sarana dan prasarana, mentor dan materi yang diajarkan). 3) Model pembelajaran ini dapat diterapkan kepada seluruh peserta KMB, karena yang diajarkan merupakan prinsip-prinsip dasar dalam membangun sebuah model bisnis. 4) Sebelum pengelompokkan, mungkin sebaiknya ada wawancara/kuesioner khusus untuk mengetahui tingkat pemahaman calon mentee, tidak hanya skala usahanya saja. 5) Bagi calon mentee yg baru ingin memulai dan awam, mungkin perlu juga ada materi pendahuluan khusus (example: motivasi, tujuan bisnis Ifinance, "why", dsb) Sehingga penyampaian materi bisa diterima dgn efektif, tidak banyak ketidak mengertian dalam istilah-istilah khusus, dan tepat sasaran.

\section{SIMPULAN DAN SARAN}

\section{Simpulan}

Dari hasil Pengabdian Masyarakat ini diperoleh kesimpulan bahwa Program KMB pada kepengurusan TDA Jaksel 5.0 adalah sebagai berikut: 1) Telah dilakukan perbaikan program KMB dengan mengacu pada konsep pelatihan yang efektif yang berfokus pada "regrouping" peserta KMB sesuai dengan level bisnis peserta. Telah dikembangkan pula 
kurikulum mini kewirausahaan pada program KMB TDA Jaksel 5.0 utamanya untuk group basic yang mengacu pada materi yang disertai template agar peserta dapat menggunakan tools ini nantinya pada implementasi bisnis mereka serta penambahan materi motivasi. 2) Dengan adanya perbaikan program ini efektifitas program KMB bisa di capai dan menurut survei yang dilakukan pada group basic terlihat bahwa kepuasan mereka meningkat 25\%. Hasil akhir yang diperoleh dengan adanya perbaikan program ini efektifitas program KMB bisa di capai.

\section{Saran}

Diharapkan kelompok lain bisa menggunakan konsep perbaikan ini dengan penyesuaian pendekatan dengan melihat kebutuhan masing masing kelompok/level. Selain itu evaluasi kedepannya bisa dilakukan pada hasil program KMB ini tidak sekedar mengukur kepuasan saja.

\section{DAFTAR PUSTAKA}

Ciputraentrepreneurship.com.

(2013).

Dibandingkan dengan Malaysia dan Singapura Daya Saing Indonesia Lemah Karena Kurang Jumlah Wirausaha. Diakses dari http://ww.ciputraentrepreneurship.com/ berita-ce/23529-dibandingkan-malaysia-

dan singapura-daya-saing-indonesia-lemahkarena-kurang-jumlah-wirausaha.html. pada 3 Juli 2013.

Ino Yuwono, Fendy Suhariadi, Seger Handoyo, Fajrianthi, Budi Setiawan Muhamad, Berlian Gressy Septarini. (2015). Psikologi Industri \& Organisasi. Surabaya: Fakultas Psikologi Universitas Airlangga

Jurnas.com. (2013). Jumlah Wirausaha di Indonesia Ditargetkan 2,50 Persen. Diakses dari http://www.jurnas.com/news/92031/201 3,_Jumlah_Wirausaha_di_Indonesia_Ditar getkan_2,50_Persen/1/Ekonomi/Ekonomi pada 2 Juli 2013.

Kementerian Koperasi dan UKM RI. Laporan Kinerja 2011. Kebangkitan Koperasi dan UMNKM: Menuju Kesejahteraan Rakyat

Lemhannas RI. (2013). PPRA L. Modul BS Ketahanan Nasional.

Lemhannas RI. (2013). PPRA L. Bahan-bahan Ceramah Tajar BS. Lingkungan Strategis Kontemporer, SBS. Isu Global Kontemporer. Kementrian Perindustrian RI. (2013). UKM Harus Tingkatkan Daya Saing. Diakses dari http://www.kemenperin.go.id/artikel/6058/U KM-Harus-Tingkatkan-Daya-Saing pada 2 Juli 2013. 